\title{
OPEN Complete plastomes of six species of Wikstroemia (Thymelaeaceae) reveal paraphyly with the monotypic genus Stellera
}

\author{
Liefen $\mathrm{He}^{1}$, Yonghong Zhang ${ }^{1 \bowtie}$ \& Shiou Yih Lee ${ }^{2 \bowtie}$
}

Wikstroemia (Thymelaeaceae) is a diverse genus that extends from Asia to Australia and has been recorded on the Hawaiian Islands. Despite its medicinal properties and resource utilization in pulp production, genetic studies of the species in this important genus have been neglected. In this study, the plastome sequences of six species of Wikstroemia were sequenced and analysed. The plastomes ranged in size between $172,610 \mathrm{bp}$ (W. micrantha) and 173,697 bp (W. alternifolia) and exhibited a typical genome structure consisting of a pair of inverted repeat (IR) regions separated by a large single-copy (LSC) region and a small single-copy (SSC) region. The six plastomes were similar in the 138 or 139 genes predicted, which consisted of 92 or 93 protein-coding genes, 38 tRNA genes, and 8 rRNA genes. The overall GC contents were identical (36.7\%). Comparative genomic analyses were conducted with the inclusion of two additional published species of Wikstroemia in which the sequence divergence and expansion of IRs in the plastomes were determined. When compared to the coding sequences (CDSs) of Aquilaria sinensis, five genes, namely, rpl2, rps7, rps18, ycf1 and ycf2, indicated positive selection in W. capitata. The plastome-based phylogenetic analysis inferred that Wikstroemia in its current state is paraphyletic to Stellera chamaejasme, while the ITS-based tree analyses could not properly resolve the phylogenetic relationship between Stellera and Wikstroemia. This finding rekindled interest in the proposal to synonymize Stellera with Wikstroemia, which was previously proposed but rejected due to taxonomic conflicts. Nevertheless, this study provides valuable genomic information to aid in the taxonomic implications and phylogenomic reconstruction of Thymelaeaceae.

Wikstroemia Engl. (Thymelaeaceae) is a diverse genus of approximately 70 species. Members of Wikstroemia are widely distributed in the Asian and Oceanian regions and scattered around the Hawaiian Islands ${ }^{1}$. The species are mostly fibrous trees, shrubs or subshrubs with a woody rhizome. Several species are cultivated as raw material for pulp production ${ }^{2,3}$, while a handful of them are reported to have medicinal properties ${ }^{4,5}$. However, studies of Wikstroemia have been confined to its utilization in pulp production and pharmacological applications; reports on genetic studies of Wikstroemia are scarce.

The only reports on the genetic diversity to date include one on Wikstroemia ganpi in Korea using inter simple sequence repeat (ISSR) markers ${ }^{6}$ and two, published, complete plastome sequences of Wikstroemia chamaedaphne and Wikstroemia indica ${ }^{7,8}$. Due to the lack of molecular evidence, taxonomic studies of Wikstroemia have relied solely on morphological characteristics ${ }^{9}$. Ironically, the continuous nature of morphological variation in members of Wikstroemia has led to much taxonomic confusion in attempts to distinguish species and has resulted in ambiguities in taxonomic classifications between Wikstroemia and its sister genera ${ }^{9,10}$. Among the key morphological characteristics proposed to differentiate Wikstroemia from allied genera is the presence of petaloid scales in the flower ${ }^{11}$. However, the presence and characteristics of the disc in the flowers of Wikstroemia was not emphasized. Failure to analyse this character may result in misidentifications due to overlap in this feature during classification ${ }^{10}$. The subgeneric classification of Wikstroemia, consisting of only the subgenera Wikstroemia and Diplomorpha, is generally accepted ${ }^{12,13}$. Another problem in classification is the difficulty in detecting natural hybridization among the species due to the possibility of low reproductive isolation and high genetic similarity, suggesting that Wikstroemia represents a large complex of species ${ }^{14}$.

${ }^{1}$ School of Life Sciences, Yunnan Normal University, Kunming, China. ${ }^{2}$ State Key Laboratory of Biocontrol and Guangdong Provincial Key Laboratory of Plant Resources, School of Life Sciences, Sun Yat-sen University, Guangzhou, China. ${ }^{\circledR}$ email: daphnecn@aliyun.com; leesy3@mail.sysu.edu.cn 


\begin{tabular}{|c|c|c|c|c|c|c|c|c|c|c|c|c|c|c|c|c|c|}
\hline \multirow[b]{2}{*}{ Species } & \multirow[b]{2}{*}{ Origin } & \multirow[b]{2}{*}{$\begin{array}{l}\text { Collector } \\
\text { and } \\
\text { collection } \\
\text { number }\end{array}$} & \multirow[b]{2}{*}{$\begin{array}{l}\text { Coordinates } \\
\text { (longitude, } \\
\text { latitude) }\end{array}$} & \multicolumn{8}{|c|}{ Plastome } & \multicolumn{4}{|c|}{ Plastid genes } & \multicolumn{2}{|c|}{$\begin{array}{l}\text { GenBank accession } \\
\text { number }\end{array}$} \\
\hline & & & & $\begin{array}{l}\text { Total } \\
\text { (bp) }\end{array}$ & \begin{tabular}{l|} 
GC \\
content \\
$(\%)$
\end{tabular} & $\begin{array}{l}\text { LSC } \\
\text { (bp) }\end{array}$ & $\begin{array}{l}\text { GC } \\
\text { content } \\
(\%)\end{array}$ & $\begin{array}{l}\text { SSC } \\
\text { (bp) }\end{array}$ & $\begin{array}{l}\text { GC } \\
\text { content } \\
(\%)\end{array}$ & $\begin{array}{l}\text { IR } \\
\text { (bp) }\end{array}$ & \begin{tabular}{|l|} 
GC \\
content \\
$(\%)$
\end{tabular} & Total & CDS & tRNA & rRNA & Plastome & ITS \\
\hline $\begin{array}{l}\text { Wik- } \\
\text { stro- } \\
\text { emia } \\
\text { alterni- } \\
\text { folia }\end{array}$ & $\begin{array}{l}\text { Batang } \\
\text { County, } \\
\text { Sichuan }\end{array}$ & $\begin{array}{l}\text { Y. H. } \\
\text { Zhang } \\
\text { et al., } \\
\text { RXK30 }\end{array}$ & $\begin{array}{l}29^{\circ} 19^{\prime} 27^{\prime \prime} \mathrm{N} \\
99^{\circ} 18^{\prime} 40^{\prime \prime} \mathrm{E}\end{array}$ & 173,697 & 36.7 & 86,694 & 34.8 & 2857 & 29.5 & 42,073 & 38.8 & 139 & 93 & 38 & 8 & MW073913 & MW075476 \\
\hline $\begin{array}{l}\text { Wik- } \\
\text { stro- } \\
\text { emia } \\
\text { canes- } \\
\text { cens }\end{array}$ & $\begin{array}{l}\text { Batang } \\
\text { County, } \\
\text { Sichuan }\end{array}$ & $\begin{array}{l}\text { Y. H. } \\
\text { Zhang } \\
\text { et al., } \\
\text { RXK32 }\end{array}$ & $\begin{array}{l}29^{\circ} 19^{\prime} 27^{\prime \prime} \mathrm{N} \\
99^{\circ} 18^{\prime} 40^{\prime \prime} \mathrm{E}\end{array}$ & 173,667 & 36.7 & 86,701 & 34.8 & 2854 & 29.6 & 42,056 & 38.8 & 139 & 93 & 38 & 8 & MW073911 & MW075477 \\
\hline $\begin{array}{l}\text { Wik- } \\
\text { stro- } \\
\text { emia } \\
\text { capitata }\end{array}$ & $\begin{array}{l}\text { Guan- } \\
\text { yang, } \\
\text { Wushan } \\
\text { County, } \\
\text { Chong- } \\
\text { qing }\end{array}$ & $\begin{array}{l}\text { Y. H. } \\
\text { Zhang and } \\
\text { W. G. Sun, } \\
\text { RXK33 }\end{array}$ & $\begin{array}{l}31^{\circ} 28^{\prime} 02^{\prime \prime} \mathrm{N} \\
109^{\circ} 55^{\prime} 53^{\prime \prime} \mathrm{E}\end{array}$ & 172,849 & 36.7 & 86,154 & 34.8 & 2871 & 29.4 & 41,912 & 38.9 & 138 & 92 & 38 & 8 & MW073909 & MW075480 \\
\hline $\begin{array}{l}\text { Wik- } \\
\text { stro- } \\
\text { emia } \\
\text { doli- } \\
\text { cantha }\end{array}$ & $\begin{array}{l}\text { Kun- } \\
\text { ming, } \\
\text { Yunnan }\end{array}$ & $\begin{array}{l}\text { Y. H. } \\
\text { Zhang et al. } \\
\text { RXK39 }\end{array}$ & $\begin{array}{l}25^{\circ} 07^{\prime} 48^{\prime \prime} \mathrm{N} \\
102^{\circ} 42^{\prime} 24^{\prime \prime} \mathrm{E}\end{array}$ & 172,804 & 36.7 & 86,230 & 34.8 & 2854 & 28.7 & 41,860 & 38.9 & 138 & 92 & 38 & 8 & MW073912 & MW075475 \\
\hline $\begin{array}{l}\text { Wik- } \\
\text { stro- } \\
\text { emia } \\
\text { micran- } \\
\text { tha }\end{array}$ & $\begin{array}{l}\text { Chang- } \\
\text { shou } \\
\text { County, } \\
\text { Chong- } \\
\text { qing }\end{array}$ & $\begin{array}{l}\text { Y. H. } \\
\text { Zhang et al. } \\
\text { S0693- } \\
\text { Zhang4 }\end{array}$ & $\begin{array}{l}29^{\circ} 49^{\prime} 02^{\prime \prime} \mathrm{N} \\
107^{\circ} 4^{\prime} 35^{\prime \prime} \mathrm{E}\end{array}$ & 172,610 & 36.7 & 86,111 & 34.9 & 2799 & 29.5 & 41,850 & 38.9 & 139 & 93 & 38 & 8 & MN756675 & MW075479 \\
\hline $\begin{array}{l}\text { Wik- } \\
\text { stro- } \\
\text { emia } \\
\text { scyto- } \\
\text { phylla }\end{array}$ & $\begin{array}{l}\text { Kun- } \\
\text { ming } \\
\text { Botani- } \\
\text { cal } \\
\text { Garden }\end{array}$ & $\begin{array}{l}\text { Y. H. } \\
\text { Zhang, } \\
\text { et al. } \\
\text { RXK48 }\end{array}$ & $\begin{array}{l}25^{\circ} 08^{\prime} 36^{\prime \prime} \mathrm{N} \\
102^{\circ} 44^{\prime} 27^{\prime \prime} \mathrm{E}\end{array}$ & 173,254 & 36.7 & 86,338 & 34.8 & 2840 & 29.4 & 42,038 & 38.8 & 139 & 93 & 38 & 8 & MW073910 & MW075474 \\
\hline
\end{tabular}

Table 1. Plastome features of six species of Wikstroemia.

The plastome is a circular double-stranded DNA molecule. In plants, the plastome is mostly maternally inherited and not disturbed by gene recombination ${ }^{15}$. A typical plant plastome ranges in size from 120 to $217 \mathrm{~kb}^{16}$. The complete plastome has a typical quadripartite structure, including a large single-copy (LSC) region, a small single-copy (SSC) region, and two separate inverted regions (IRs) ${ }^{17}$. Owing to its slow rate of evolution and ease of sequencing and assembly due to its small size, the plastome has been receiving much attention among biologist and taxonomist because it is highly informative and provides evolutionary and genetics insights ${ }^{18,19}$.

The taxonomic placement of Wikstroemia has been controversial. This genus has experienced a complicated classification history in reviews of members of the Thymelaeaceae. Stellera chamaejasme of the monotypic genus Stellera was reported to be sister to Wikstroemia based on combined plastid DNA sequences (trnT-trnL, trnL-trnF, trnL intron, and $r p l 16$ intron $)^{20}$, while Wikstroemia, along with 14 sister genera based on palynology findings, has been taxonomically placed in the Daphne group of the tribe Daphneae ${ }^{21,22}$. Although phylogenetic studies in Thymelaeaceae are ongoing ${ }^{23}$, phylogenetic relationships in Wikstroemia are likely to be understudied. Constituent genera in Thymelaeaceae have experienced similar molecular challenges, in which poor phylogenetic resolution is likely due to low genetic variation in the selected molecular markers ${ }^{23}$. Such conflicts can be overcome by utilizing genome-scale datasets ${ }^{24}$. At the same time, highly divergent regions may be identified through genome comparisons, which could aid in future phylogenetic studies of such a diverse genus as Wikstroemia.

In this study, we sequenced the complete plastomes of six species of Wikstroemia, W. alternifolia, W. canescens, W. capitata, W. dolicantha, W. micrantha, and W. scytophylla, to analyse and compare genomes using bioinformatic tools. Our aims were to (1) characterize the plastomes of the six species of Wikstroemia; (2) examine the variation in sequence repeats and codon usage in the six plastome sequences; (3) identify highly divergent regions in the plastome sequences; and (4) improve the understanding of the intrageneric/intergeneric phylogeny of Wikstroemia within Thymelaeaceae based on plastome sequences and the nuclear ribosomal DNA internal transcribed spacer (ITS) region.

\section{Results}

Plastome features of six species of Wikstroemia. The total length of the plastomes of the six species of Wikstroemia analysed in this study ranged from $172,610 \mathrm{bp}$ (W. micrantha) to 173,697 bp (W. alternifolia). All six plastomes exhibited a typical quadripartite structure (Table 1, Fig. 1) consisting of a pair of inverted repeat (IR) regions (41,850-42,073 bp) separated by an LSC region (86,111-86,701 bp) and an SSC region (2799-2871 bp). All six plastomes had the same GC content at $36.7 \%$. However, the GC content in the plastome of each species of Wikstroemia was unevenly distributed. The IR region accounted for the highest GC content (38.8-38.9\%), followed by the LSC region (34.8-34.9\%), while the SSC region showed the lowest GC content (28.7-29.6\%). 


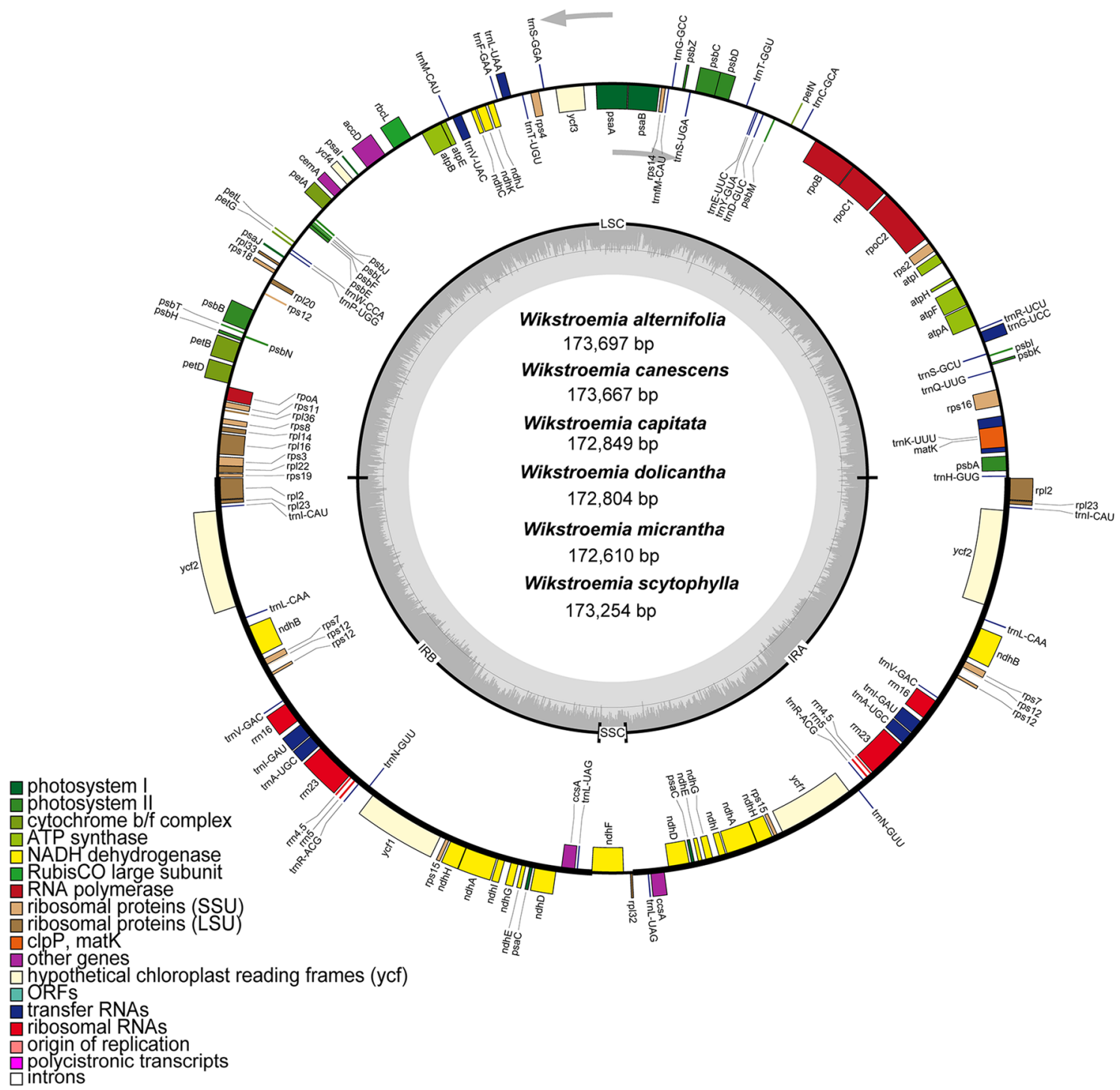

Figure 1. Gene map for the plastomes of six species of Wikstroemia used in this study. Genes on the inside of the map are transcribed in the clockwise direction; genes on the outside of the map are transcribed in the counterclockwise direction. Darker grey in the inner circle represents the GC content, whereas light grey corresponds to the AT content. Different functional groups of genes are shown in different colours. The gene map was generated using OGDRAW ${ }^{45}$.

The six plastomes of Wikstroemia displayed an identical gene content and gene order with no structural reconfigurations. A total of 138 to 139 genes were detected in the six species used in this study, comprising 92 to 93 protein-coding genes, 38 transfer RNA (tRNA) genes, and 8 ribosomal RNA (rRNA) genes (Table 1). However, 27 genes were duplicated in the IR regions, including 15 protein-coding genes $(c c s \mathrm{~A}, n d h \mathrm{~A}, n d h \mathrm{~B}, n d h \mathrm{D}, n d h \mathrm{E}$, $n d h \mathrm{H}, n d h \mathrm{G}, n d h \mathrm{I}, p s a \mathrm{C}, r p l 2, r p l 23, r p s 7, r p s 15, y c f 1, y c f 2)$, eight tRNA genes (trnA-UGC, trnI-CAU, trnI-GAU,

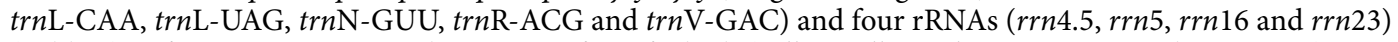
(Table 2). Fifteen genes contained an intron, five of which ( $n d h \mathrm{~A}, n d h \mathrm{~B}, r p l 2, \operatorname{trnA}-\mathrm{UGC}$ and $\operatorname{trnI} \mathrm{I}-\mathrm{GAU})$ were located in the IR region, and the remaining 10 genes $(a t p \mathrm{~F}, p e t \mathrm{~B}, p e t \mathrm{D}, r p l 16, r p o \mathrm{C} 1, r p s 16, \operatorname{trn\mathrm {G}}-\mathrm{UCC}$, $\operatorname{trn\mathrm {L}}$ UAA, trnK-UUU and $t r n \mathrm{~V}$-UAC) were located in the LSC region (see Supplementary Table S1 online). Only the $y c f 3$ gene, which was present in the LSC region, was detected to contain a pair of introns. Upon comparison, we found that the trnK-UUU gene had the longest intron, ranging from 2498 to $2508 \mathrm{bp}$, in all six genomes.

Repetitive sequence analysis. The total number of short sequence repeats (SSRs) in the plastome sequences of $W$. alternifolia, W. canescens, W. capitata, W. dolicantha, W. micrantha, and W. scytophylla were 127, 128, 110, 87, 90 and 110, respectively (Fig. 2A). No hexanucleotide sequences, however, were detected in the plastome sequences of W. alternifolia, W. canescens and W. scytophylla. The majority of SSRs (W. alternifolia: 70.87\%; W. canescens: 70.31\%; W. capitata: 68.18\%; W. dolicantha: 63.22\%; W. micrantha: 61.11\%, W. scytophylla: $63.64 \%$ ) were located in the LSC regions rather than in the other two regions of the plastome (Fig. 2B). 


\begin{tabular}{|c|c|}
\hline & Genes \\
\hline RNAs, ribosomal & $r r n 4.5(\times 2), r r n 5(\times 2), r r n 16(\times 2), r r n 23(\times 2)$ \\
\hline RNAs, transfer & 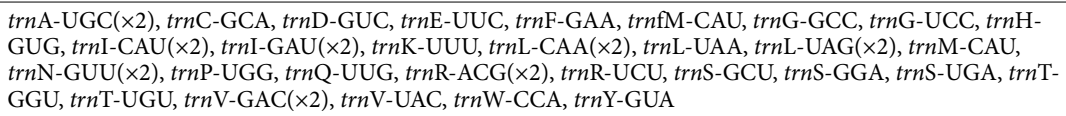 \\
\hline Transcription and splicing & matK, rpoA, rpoB, rpoC1, rpoC2 \\
\hline Small subunit & $r p s 3, r p s 4, r p s 7(\times 2), r p s 8, r p s 11, r p s 12, r p s 14, r p s 15(\times 2), r p s 16, r p s 18, r p s 19$ \\
\hline Large subunit & $r p l 2(\times 2), r p l 14, r p l 16, r p l 20, r p l 22, r p l 23(\times 2), r p l 32, r p l 33, r p l 36$ \\
\hline ATP synthase & $\operatorname{atp} \mathrm{A}, \operatorname{atp} \mathrm{B}, a t p \mathrm{E}, a t p \mathrm{~F}, \operatorname{atp} \mathrm{H}, a t p \mathrm{I}$ \\
\hline Photosystem I & $p s a \mathrm{~A}, p s a \mathrm{~B}, p s a \mathrm{C}(\times 2), p s a \mathrm{I}, p s a \mathrm{~J}$ \\
\hline Photosystem II & $p s b \mathrm{~A}, p s b \mathrm{~B}, p s b \mathrm{C}, p s b \mathrm{D}, p s b \mathrm{E}, p s b \mathrm{~F}, p s b \mathrm{H}, p s b \mathrm{I}, p s b \mathrm{~J}, p s b \mathrm{~K}, p s b \mathrm{~L}, p s b \mathrm{M}, p s b \mathrm{~N}, p s b \mathrm{~T}, p s b \mathrm{Z}$ \\
\hline Calvin cycle & $r b c \mathrm{~L}$ \\
\hline Cytochrome complex & 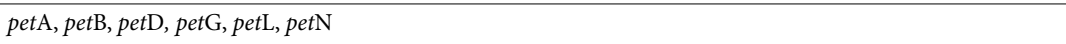 \\
\hline NADH dehydrogenase & $n d h \mathrm{~A}(\times 2), n d h \mathrm{~B}(\times 2), n d h \mathrm{C}, n d h \mathrm{D}(\times 2), n d h \mathrm{E}(\times 2), n d h \mathrm{~F}, n d h \mathrm{G}(\times 2), n d h \mathrm{H}(\times 2), n d h \mathrm{I}(\times 2), n d h \mathrm{~J}, n d h \mathrm{~K}$ \\
\hline Others & $a c c \mathrm{D}, c c s \mathrm{~A}(\times 2), c e m \mathrm{~A}, y c f 1(\times 2), y c f 2(\times 2), y c f 3, y c f 4$ \\
\hline
\end{tabular}

Table 2. Genes present in the plastomes of six species of Wikstroemia used in this study.

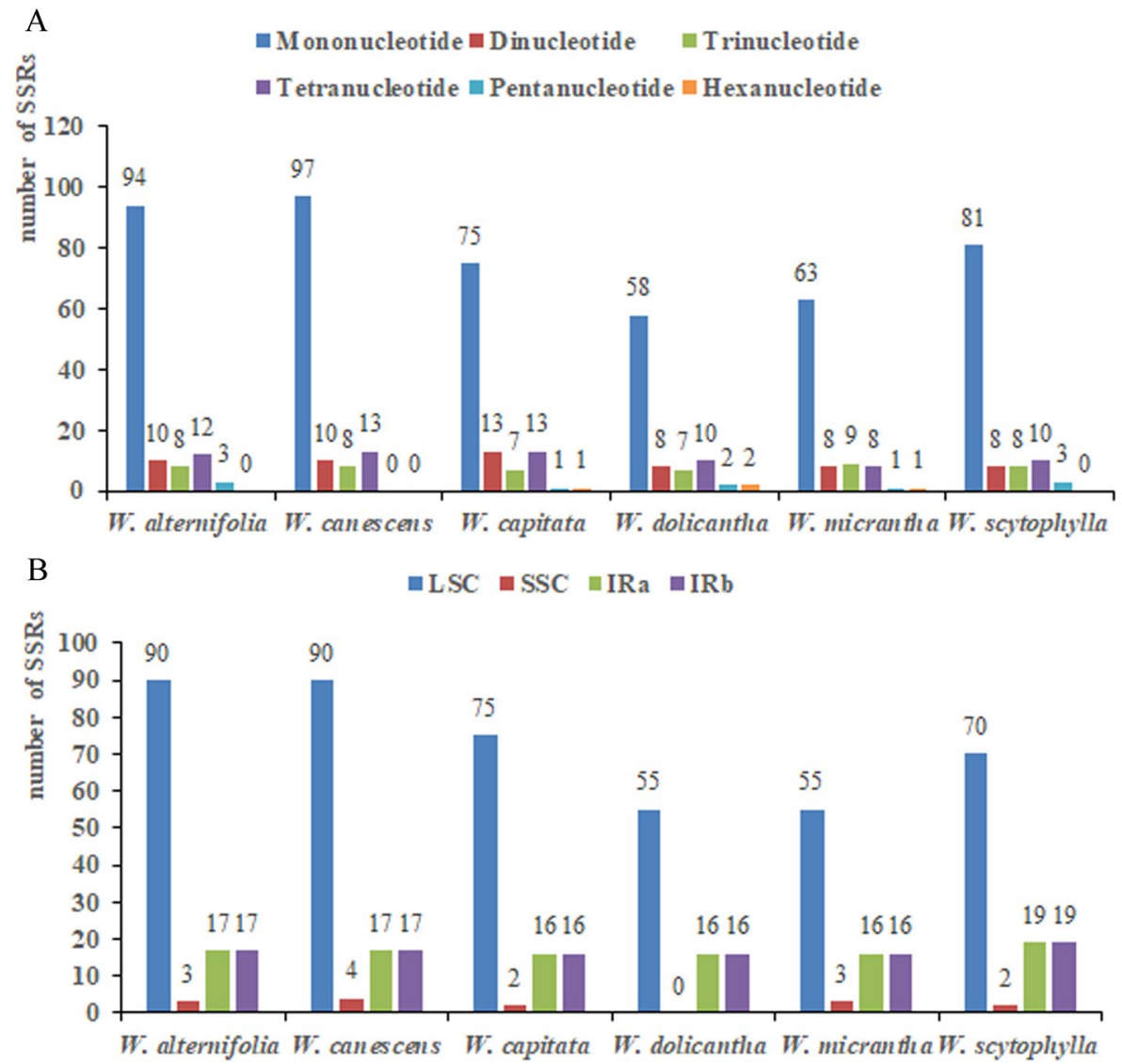

Figure 2. Distribution of small sequence repeats (SSRs) in the plastomes of six accessions of Wikstroemia. (A) Number of different SSR types detected in the plastomes of six species of Wikstroemia; (B) Frequencies of identified SSRs in large single-copy (LSC), small single-copy (SSC) and inverted repeat (IR) regions.

All six species of Wikstroemia contained the same number of long repeats (Fig. 3A). In general, all of them contained 24 forward repeats and 25 palindromic repeats, except for W. canescens and W. capitata. Long forward repeats that ranged between 30 and $40 \mathrm{bp}$ were the most abundant in $W$. dolicantha and W. micrantha, while W. alternifolia, W. canescens, W. capitata, and W. scytophylla were noted to have a higher number of long forward repeats with lengths of 41 to $60 \mathrm{bp}$ (Fig. 3B). Long palindromic repeats were equally abundant in W. alternifolia and $W$. canescens, ranging from 40 to $60 \mathrm{bp}$ and above $60 \mathrm{bp}$ (Fig. 3C), while long palindromic repeats were 
A



$\mathrm{C}$

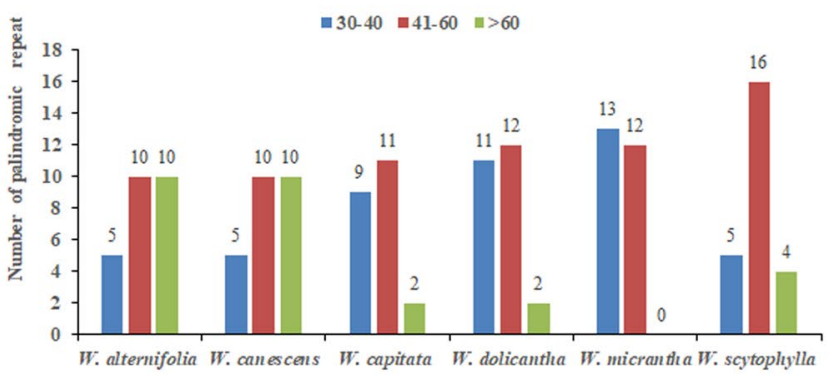

B

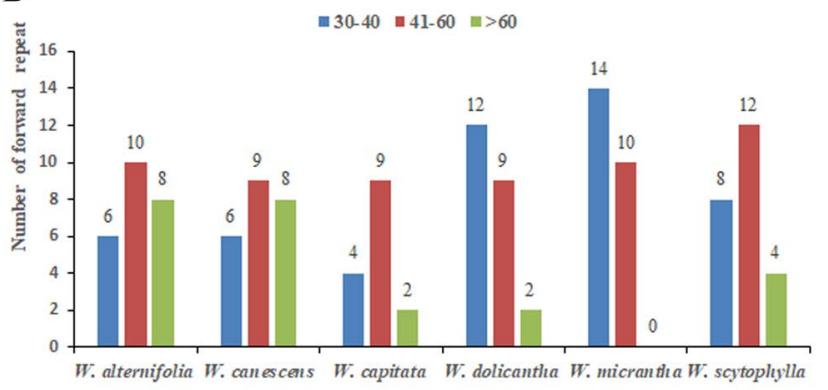

D

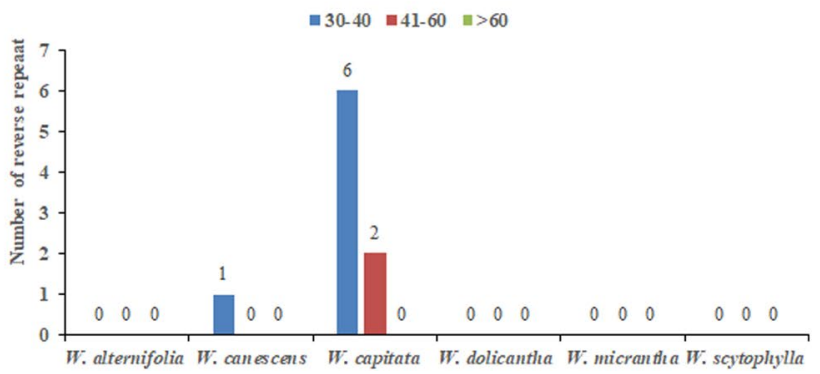

Figure 3. Analysis of long repeat sequences in the plastomes of six species of Wikstroemia. (A) Quantities of long repeats based on type; (B) frequencies of forward repeats by length; (C) frequencies of palindromic repeats by length; and (D) frequencies of reverse repeats by length.

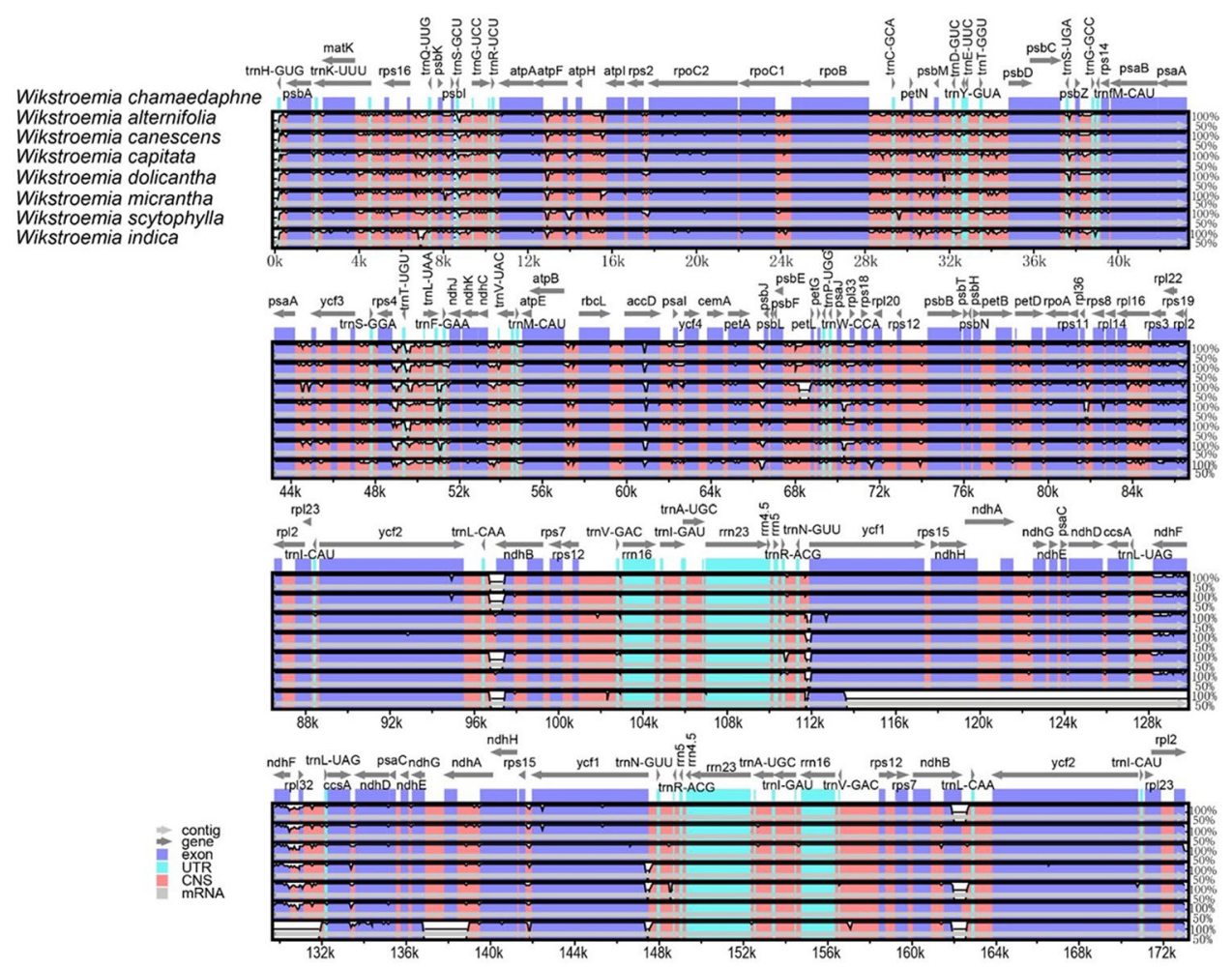

Figure 4. Complete plastome comparison of eight species of Wikstroemia using the plastome of $W$. chamaedaphne as reference.

abundant in the range of 30 to $60 \mathrm{bp}$ in W. capitata, W. dolicantha, W. micrantha and W. scytophylla. Long reverse repeats, mostly within the range of 30 to $40 \mathrm{bp}$, were detected only in W. canescens and W. capitata (Fig. 3D).

Analysis of codon usage. Thirty preferred codons (relative synonymous codon usage; RSCU $>1.00$ ) were recorded in W. alternifolia, W. canescens, W. capitata, W. dolicantha, W. micrantha and W. scytophylla (see Sup- 


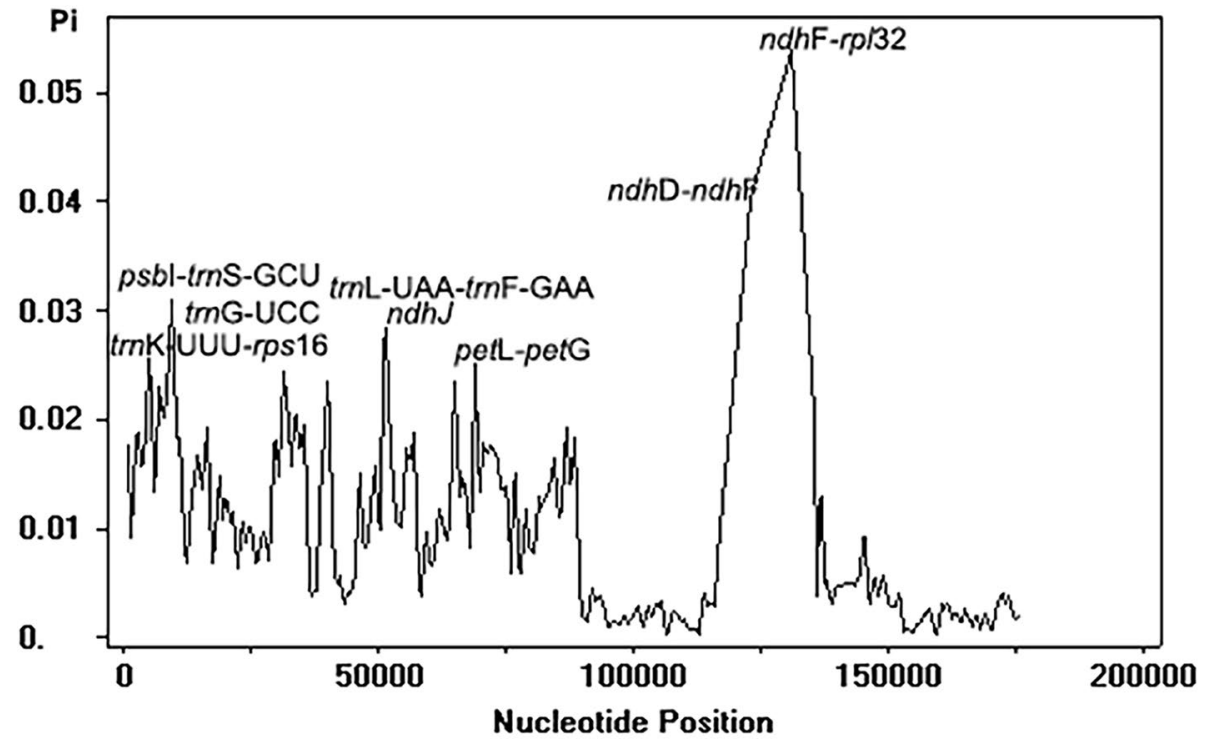

Figure 5. Sliding window analysis of complete plastome sequences among eight species of Wikstroemia (window length: $1000 \mathrm{bp}$; step size: $500 \mathrm{bp}$ ).

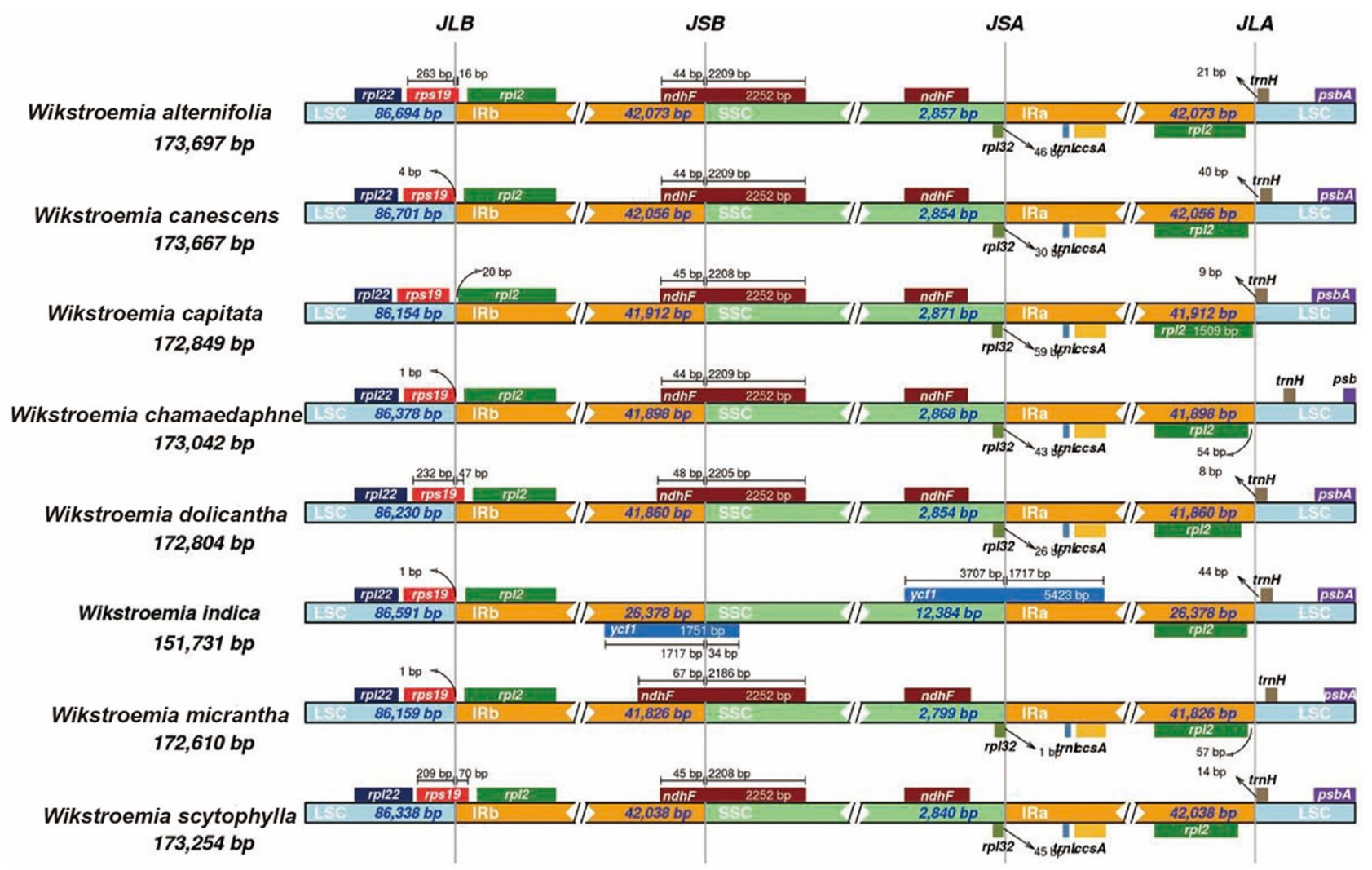

Figure 6. Comparison of borders between LSC, SSC and IR regions across the plastomes of eight species of Wikstroemia. Image was generated with IRscope ${ }^{50}$.

plementary Table S2 online). The stop codon UAA was most abundant and preferred over the other two stop codons, UAG and UGA, in all six species. Preferred codons mostly ended with the amino acids A or U, except for the leucine-encoded (Leu) codon UUG. The Leu-encoded codons had the greatest occurrence (9.38\%), while cysteine-encoded (Cys) codons had the fewest occurrences (3.13\%) among all six species of Wikstroemia. 
Sequence divergence analysis. The plastome sequence alignment of the eight species of Wikstroemia, using the $W$. chamaedaphne plastome as a reference, indicated high sequence conservatism across the plastomes of eight species but not in the plastome of $W$. indica (Fig. 4). Overall, the size and gene order of the plastomes in Wikstroemia were well conserved, but a distinct large gap was observed beginning within the $y c f 1$ gene sequence of the IRa to $5^{\prime}$ region of the trnL-UAG in the IRb of $W$. indica. Both single-copy regions were recorded as having greater sequence divergence than the IR region (Fig. 5). With a Pi-value cut-off point of 0.025 , eight highly variable gene regions were identified: $n d h \mathrm{D}-n d h \mathrm{~F}, n d h \mathrm{~F}-r p l 32, n d h \mathrm{~J}$, petL-petG, $p s b \mathrm{I}-\operatorname{trnS}-\mathrm{GCU}, \operatorname{trn} \mathrm{G}-\mathrm{UCC}, \operatorname{trn\mathrm {K}}-$ UUU-rps 16 and the trnL-UAA-trnF-GAA intergenic spacer regions. Six of the highly variable regions were located in the LSC, while two of them were in the SSC region.

Contraction and expansion in the IR region. Genes adjacent to the IR borders were consistent across members of Wikstroemia, except in W. indica, which varied in its adjacent genes at the IRb/SSC (JSB) and IRa/ SSC (JSA) borders (Fig. 6). In contrast to the rpl32 and $n d h \mathrm{~F}$ genes in the SSC region, adjacent to JSB and JSA, respectively, the $y c f 1$ gene was located across both JSA and JSB in the plastomes of $W$. indica. The trnL-UAG gene was also adjacent to JSA in the SSC region of the $W$. indica plastome. In comparison, six species (W. alternifolia, W. chamaedaphne, W. dolicantha, W. indica, W. micrantha and W. scytophylla) had their rps 19 gene crossing the $\mathrm{IRb} / \mathrm{LSC}(\mathrm{JLB})$ border.

Selection pressure. Sixty-nine shared protein-coding genes were included in the selection pressure analysis between Aquilaria sinensis and W. capitata (Table 3 ). When analysed separately, the $\mathrm{K}_{\mathrm{a}} / \mathrm{K}_{\mathrm{s}}$ values indicated that five genes, namely, $r p l 2, r p s 7, r p s 18, y c f 1$ and $y c f 2$, displayed positive selection; 61 genes indicated purifying selection, and three genes did not exhibit any synonymous $\left(\mathrm{K}_{\mathrm{s}}\right)$ values indicative of selection due to the constraints of the model used. The $\mathrm{K}_{\mathrm{a}} / \mathrm{K}_{\mathrm{s}}$ value for the combined dataset revealed that the overall selection pressure of the 69 shared protein-coding genes was 0.435 , showing signals of purifying selection.

Phylogenetic analysis. The maximum-likelihood (ML) and Bayesian inference (BI) trees based on the complete plastome sequences excluding the IRa sequences and the dataset of the intergenic spacer (IGS) sequences revealed that all the branch nodes for eight species of Wikstroemia included in the phylogenetic tree were supported with high bootstrap values and Bayesian posterior probabilities (ML: $\geq 90 \%$; BI: $\geq 95 \%$ ) (Fig. 7). For the dataset of the total gene sequences containing protein-coding genes, tRNAs, and rRNAs that are shared by all species, strong posterior probabilities were recorded in most of the branch nodes of the BI tree but not in the ML tree, in which moderate bootstrap support was recorded for the backbone structure of the Wikstroemia clade (see Supplementary Figure S1 online). The molecular placement of W. capitata and W. indica, forming sister to each other under low branch support, in the ML tree and BI tree based on the dataset of all protein-coding genes was incongruent with the phylogenetic trees based on the datasets using complete plastome sequences excluding the IRa and intergenic spacer (IGS) sequences. The ML trees and BI trees based on the datasets of the first, second, and third codons of each amino acid in the protein-coding sequences did not display matching molecular placement of Wikstroemia when compared with each other; most of the branches were poorly supported in the Wikstroemia clade (see Supplementary Figure S2 online). The phylogenetic tree using complete plastome sequences excluding the IRa sequences suggested that a paraphyletic relationship was present in Wikstroemia. Two species, W. alternifolia and W. canescens, were clustered with Stellera chamaejasme, while six species of Wikstroemia (W. capitata, W. chamaedaphne, W. dolicantha, W. indica, W. micrantha and W. scytophylla) formed a monophyletic group.

The ITS-based ML tree revealed a paraphyletic relationship between Wikstroemia and S. chamaejasme, while most of the branch nodes within the Wikstroemia clade were not highly supported (Fig. 8A). Strong bootstrap support was recorded for the sistership between W. alternifolia and W. canescens and between W. micrantha and W. stenophylla. Weakly supported sisterships were present between W. dolicantha and W. scytophylla and between $W$. capitata and W. ligustrina. In contrast, the BI analysis displayed a monophyletic relationship within the Wikstroemia clade (Fig. 8B). Similar to the ML tree, sisterships were strongly supported between W. alternifolia and $W$. canescens and between W. micrantha and W. stenophylla but not between W. dolicantha and W. scytophylla or between W. capitata and W. ligustrina in the BI tree.

\section{Discussion}

The plastomes of the species in Wikstroemia examined in this study were highly conserved, which is similar to the situation in other angiosperms. The length of the plastomes of the six species of Wikstroemia varied little and were similar in size to typical angiosperms ${ }^{25}$. The same number and contents of the genes were predicted in this study, suggesting that the evolution of the gene sequences was consistent across the six species. Similar to most angiosperms, sequence repeats for $\mathrm{A} / \mathrm{T}$ were more abundant than those of $\mathrm{G} / \mathrm{C}$ in the Wikstroemia plastomes and may represent bias in the base composition, which is potentially affected by the tendency of the genome to change to A-T rather than to G-C ${ }^{26}$. An additional validation step for these SSRs, for which five novel SSR primer sets were designed, was conducted for the six species of Wikstroemia reported in this study. Details of the newly designed SSR primer sets and the resulting pherograms are included for reference (see Supplementary Table S3 and Data S1 online).

Expansion and contraction of the IR region are major evolutionary events that influence the length of the plastomes ${ }^{27}$. The IR junctions in the plastomes reported in this study were placed and annotated with Geneious Prime $^{28}$ and further validated with GeSeq ${ }^{29}$ as well as Sanger sequencing using novel specific primer sets (see Supplementary Table S4 and Data S2 online). Our study indicated that the contractions and expansions of the IR regions exhibited relatively stable patterns within Wikstroemia, with slight variation; gene recombination 


\begin{tabular}{|c|c|c|c|c|c|c|c|}
\hline No. & Gene & $\mathrm{K}_{\mathrm{a}}$ & $\mathrm{K}_{\mathrm{s}}$ & $\mathrm{K}_{\mathrm{a}} / \mathrm{K}_{\mathrm{s}}$ & P-value & Length of alignment (bp) & No. of substitutions \\
\hline 1 & $a c c \mathrm{D}$ & 0.1378 & 0.2406 & 0.5725 & 0.0039 & 1254 & 176 \\
\hline 2 & atpA & 0.0201 & 0.1416 & 0.1417 & 0.0000 & 1518 & 67 \\
\hline 3 & $\operatorname{atp} \mathrm{B}$ & 0.0073 & 0.0956 & 0.0760 & 0.0000 & 1494 & 42 \\
\hline 4 & $\operatorname{atp} \mathrm{E}$ & 0.0203 & 0.0873 & 0.2321 & 0.0083 & 399 & 14 \\
\hline 5 & $\operatorname{atpH}$ & 0.0113 & 0.1009 & 0.1116 & 0.0048 & 243 & 8 \\
\hline 6 & atpI & 0.0198 & 0.0651 & 0.3035 & 0.0060 & 741 & 22 \\
\hline 7 & $\operatorname{ccs} \mathrm{A}$ & 0.0123 & 0.0269 & 0.4564 & 0.1179 & 969 & 15 \\
\hline 8 & matK & 0.0580 & 0.1229 & 0.4717 & 0.0003 & 1512 & 106 \\
\hline 9 & $n d h \mathrm{~A}$ & 0.2932 & 0.3161 & 0.9273 & 0.7027 & 2001 & 488 \\
\hline 10 & $n d h \mathrm{~B}$ & \begin{tabular}{|l}
0.0050 \\
\end{tabular} & 0.0135 & 0.3699 & 0.0630 & 2052 & 14 \\
\hline 11 & $n d h \mathrm{C}$ & \begin{tabular}{|l|}
0.0137 \\
\end{tabular} & 0.1561 & 0.0877 & 0.0000 & 360 & 13 \\
\hline 12 & $n d h \mathrm{D}$ & \begin{tabular}{|l|}
0.0091 \\
\end{tabular} & 0.0134 & \begin{tabular}{|l|}
0.6809 \\
\end{tabular} & 0.4815 & 1518 & 15 \\
\hline 13 & $n d h \mathrm{E}$ & \begin{tabular}{|l|l|}
0.0000 \\
\end{tabular} & 0.0355 & 0.0000 & 0.0000 & 297 & 2 \\
\hline 14 & $n d h \mathrm{~F}$ & \begin{tabular}{|l}
0.0699 \\
\end{tabular} & 0.3206 & 0.2180 & 0.0000 & 2124 & 216 \\
\hline 15 & $n d h \mathrm{G}$ & \begin{tabular}{|l}
0.0049 \\
\end{tabular} & 0.0168 & 0.2923 & 0.2213 & 528 & 4 \\
\hline 16 & $n d h \mathrm{H}$ & \begin{tabular}{|l|}
0.0089 \\
\end{tabular} & 0.0290 & 0.3052 & 0.0175 & 1179 & 15 \\
\hline 17 & $n d h \mathrm{I}$ & \begin{tabular}{|l|}
0.0073 \\
\end{tabular} & 0.0117 & 0.6236 & 0.5313 & 501 & 4 \\
\hline 18 & $n d h \mathrm{~J}$ & \begin{tabular}{|l|l|}
0.0027 \\
\end{tabular} & 0.1144 & 0.0238 & 0.0000 & 474 & 12 \\
\hline 19 & $n d h \mathrm{~K}$ & \begin{tabular}{|l|l}
0.0271 \\
\end{tabular} & \begin{tabular}{|l|l|}
0.1467 \\
\end{tabular} & 0.1849 & 0.0000 & 681 & 34 \\
\hline 20 & pet $\mathrm{A}$ & $\mid 0.0154$ & 0.0622 & 0.2475 & 0.0007 & 960 & 25 \\
\hline 21 & pet $\mathrm{B}$ & \begin{tabular}{|l|}
0.0343 \\
\end{tabular} & 0.0618 & 0.5561 & \begin{tabular}{|l|}
0.0379 \\
\end{tabular} & 1380 & 55 \\
\hline 22 & pet $\mathrm{D}$ & \begin{tabular}{|l|l|}
0.0455 \\
\end{tabular} & 0.0623 & 0.7303 & 0.2785 & 1167 & 56 \\
\hline 23 & pet $\mathrm{G}$ & \begin{tabular}{|l|l|}
0.0000 \\
\end{tabular} & \begin{tabular}{|l|l|}
0.1517 \\
\end{tabular} & 0.0000 & 0.0000 & 108 & 4 \\
\hline 24 & pet $\mathrm{L}$ & \begin{tabular}{|l|l|}
0.0000 \\
\end{tabular} & \begin{tabular}{|l|l|}
0.1007 \\
\end{tabular} & 0.0000 & 0.0000 & 93 & 2 \\
\hline 25 & pet $\mathrm{N}$ & \begin{tabular}{|l|l|}
0.0000 \\
\end{tabular} & \begin{tabular}{|l|}
0.0947 \\
\end{tabular} & 0.0000 & 0.0000 & 87 & 2 \\
\hline 26 & $p s a \mathrm{~A}$ & \begin{tabular}{|l|l|}
0.0049 \\
\end{tabular} & 0.0877 & 0.0555 & 0.0000 & 2250 & 57 \\
\hline 27 & $p s a \mathrm{~B}$ & 0.0048 & 0.0849 & 0.0565 & 0.0000 & 2202 & 50 \\
\hline 28 & $p s a \mathrm{C}$ & \begin{tabular}{|l|l|}
0.0000 \\
\end{tabular} & 0.0199 & 0.0000 & 0.0000 & 243 & 1 \\
\hline 29 & $p s a \mathrm{I}$ & \begin{tabular}{|l|l|}
0.0242 \\
\end{tabular} & 0.0786 & 0.3074 & 0.2424 & 111 & 4 \\
\hline 30 & $p s a \mathrm{~J}$ & 0.0000 & 0.0927 & 0.0000 & 0.0000 & 132 & 3 \\
\hline 31 & $p s b \mathrm{~A}$ & \begin{tabular}{|l|l|}
0.0000 \\
\end{tabular} & 0.1473 & 0.0000 & 0.0000 & 1059 & 36 \\
\hline 32 & $p s b \mathrm{~B}$ & 0.0093 & 0.1145 & 0.0815 & 0.0000 & 1524 & 46 \\
\hline 33 & $p s b \mathrm{C}$ & \begin{tabular}{|l|l|}
0.0019 \\
\end{tabular} & \begin{tabular}{|l|}
0.0659 \\
\end{tabular} & \begin{tabular}{|l|}
0.0294 \\
\end{tabular} & 0.0000 & 1419 & 26 \\
\hline 34 & $p s b \mathrm{D}$ & $\mid 0.0062$ & \begin{tabular}{|l|}
0.0539 \\
\end{tabular} & 0.1150 & 0.0000 & 1059 & 18 \\
\hline 35 & $p s b \mathrm{E}$ & 0.0000 & 0.1038 & 0.0000 & 0.0000 & 249 & 5 \\
\hline 36 & $p s b \mathrm{~F}$ & 0.0122 & 0.1299 & 0.0938 & 0.0234 & 117 & 5 \\
\hline 37 & $p s b \mathrm{H}$ & 0.0532 & 0.1261 & 0.4222 & 0.1156 & 219 & 14 \\
\hline 38 & $p s b \mathrm{I}$ & \begin{tabular}{|l|l|}
0.0000 \\
\end{tabular} & 0.1344 & 0.0000 & 0.0000 & 108 & 4 \\
\hline 39 & $p s b \mathrm{~J}$ & \begin{tabular}{|l|}
0.0221 \\
\end{tabular} & 0.0364 & \begin{tabular}{|l|}
0.6092 \\
\end{tabular} & 0.5452 & 120 & 3 \\
\hline 40 & $p s b \mathrm{~K}$ & \begin{tabular}{|l|l|}
0.0307 \\
\end{tabular} & 0.0000 & NA & 0.0565 & 183 & 4 \\
\hline 41 & $p s b \mathrm{~L}$ & 0.0000 & 0.0388 & 0.0000 & 0.0000 & 114 & 1 \\
\hline 42 & $p s b \mathrm{M}$ & 0.0396 & 0.0433 & 0.9136 & 0.6602 & 102 & 4 \\
\hline 43 & $p s b \mathrm{~T}$ & 0.0000 & 0.2167 & 0.0000 & 0.0000 & 99 & 5 \\
\hline 44 & $p s b \mathrm{Z}$ & 0.0000 & 0.1432 & 0.0000 & 0.0000 & 186 & 5 \\
\hline 45 & $r b c \mathrm{~L}$ & \begin{tabular}{|l|}
0.0100 \\
\end{tabular} & 0.0927 & 0.1077 & 0.0000 & 1431 & 38 \\
\hline 45 & $r p l 2$ & 0.0092 & 0.0048 & 1.909 & 0.5022 & 1407 & 11 \\
\hline 46 & rpl14 & 0.0328 & 0.1322 & 0.2482 & 0.0043 & 366 & 19 \\
\hline 48 & rpl20 & 0.0496 & 0.0838 & 0.5914 & 0.3819 & 348 & 19 \\
\hline 49 & $r p l 22$ & 0.0592 & 0.1671 & 0.3540 & 0.0072 & 501 & 37 \\
\hline 50 & $r p l 23$ & 0.0091 & 0.0000 & NA & 0.0000 & 279 & 2 \\
\hline 51 & rpl32 & 0.1266 & 0.4313 & 0.2936 & 0.0075 & 153 & 22 \\
\hline 52 & rpl33 & 0.0503 & 0.1237 & 0.4068 & 0.1006 & 198 & 13 \\
\hline 53 & $r p l 36$ & 0.0357 & 0.0414 & 0.8627 & 0.6408 & 111 & 4 \\
\hline 54 & rpoA & 0.0463 & 0.1371 & 0.3378 & 0.0001 & 984 & 61 \\
\hline 55 & $r p o \mathrm{~B}$ & 0.0170 & 0.1010 & 0.1686 & 0.0000 & 3210 & 117 \\
\hline 56 & rpoC2 & 0.0346 & 0.0965 & 0.3589 & 0.0000 & 4092 & 190 \\
\hline \multicolumn{8}{|c|}{ Continued } \\
\hline
\end{tabular}




\begin{tabular}{|l|l|l|l|l|l|c|c|}
\hline No. & Gene & $\mathbf{K}_{\mathbf{a}}$ & $\mathbf{K}_{\mathbf{s}}$ & $\mathbf{K}_{\mathbf{a}} / \mathbf{K}_{\mathbf{s}}$ & P-value & Length of alignment (bp) & No. of substitutions \\
\hline 57 & $r p s 2$ & 0.0308 & 0.0555 & 0.5542 & 0.1389 & 708 & 25 \\
\hline 58 & $r p s 3$ & 0.0493 & 0.1459 & 0.3378 & 0.0011 & 654 & 42 \\
\hline 59 & $r p s 4$ & 0.0441 & 0.0946 & 0.4656 & 0.0475 & 603 & 32 \\
\hline 60 & $r p s 7$ & 0.0362 & 0.0320 & 1.131 & 0.9772 & 465 & 16 \\
\hline 61 & $r p s 8$ & 0.0361 & 0.0838 & 0.4301 & 0.0790 & 402 & 18 \\
\hline 62 & $r p s 11$ & 0.0799 & 0.1749 & 0.4567 & 0.0197 & 414 & 38 \\
\hline 63 & $r p s 14$ & 0.0351 & 0.0628 & 0.5586 & 0.2622 & 300 & 12 \\
\hline 64 & $r p s 15$ & 0.0317 & 0.0000 & NA & 0.0073 & 270 & 6 \\
\hline 65 & $r p s 18$ & 0.0634 & 0.0338 & 1.879 & 0.5130 & 276 & 15 \\
\hline 66 & $r p s 19$ & 0.0496 & 0.1094 & 0.4534 & 0.1955 & 270 & 16 \\
\hline 67 & $y c f 1$ & 0.0746 & 0.0508 & 1.469 & 0.0075 & 5316 & 353 \\
\hline 68 & $y c f 2$ & 0.0424 & 0.0141 & 3.007 & 0.0000 & 6717 & 232 \\
\hline 69 & $y c f 4$ & 0.0232 & 0.0595 & 0.3902 & 0.0567 & 561 & 17 \\
\hline 70 & Concatenated dataset & 0.0373 & 0.0857 & 0.4350 & 0.0000 & 65,172 & 3019 \\
\hline
\end{tabular}

Table 3. Selection pressure analysis of 69 shared protein-coding gene sequences for Aquilaria sinensis (GenBank accession MN720647) and Wikstroemia capitata, analysed separately and combined. NA not available.

between the repetitive sequence or poly-A structure and tRNA could be one of the reasons for the change in length in the IR region ${ }^{30}$. However, $W$. indica indicated dissimilarity in its IR borders, which differed from most angiosperms ${ }^{31}$. We suspect that the plastome IR contraction and expansion in W. indica is severe and may be due to extensive gene transfer and larger IR expansion due to the results of the double strand break repair mechanism ${ }^{32-34}$. Interestingly, when compared to other species of Wikstroemia sequenced in this study, the plastome of $W$. indica was smaller $(151,731 \mathrm{bp})$ and had a greater GC content $(37.4 \%)^{8}$. We found that the plastome of $W$. indica had a shorter IR region and larger SSC region than other species of Wikstroemia. Changes in the placement of the IR borders in the plastome of $W$. indica were likely due to contraction of the IR region, causing a loss in the number and content of the genes. Among the genes that were not found in $W$. indica but were present in other species of Wikstroemia, $n d h \mathrm{~A}, n d h \mathrm{G}$, and $n d h \mathrm{I}$ were supposed to be present in the IR


the IR regions were reduced to only one copy and were transferred to the SSC region, while the $n d h \mathrm{~F}$ and $r p l 32$ genes, common genes in the SSC region, were not detected. Therefore, it can be concluded that the contraction of the IR region that caused gene loss contributed to the difference in plastome content between $W$. indica and the other seven species of Wikstroemia.

Molecular evidence based on plastome sequences revealed a nonmonophyletic relationship between the species of Wikstroemia due to W. alternifolia and W. canescens clustering with Stellera chamaejasme. Information on the phylogenetic relationships of Wikstroemia species is scarce. Although taxonomic work is challenging in a genus with diverse species, continuous efforts among taxonomists studying members of the Thymelaeaceae have provided some insights into the taxonomic status of Wikstroemia. To provide better insight into the phylogenetic relationships at the nuclear level, we used ITS sequences to perform ML and BI analyses. Unlike phylogenomic tree analyses on complete plastome sequences, low bootstrap support and Bayesian posterior probabilities were observed at the species level in Wikstroemia. The molecular placement of the species of Wikstroemia, however, was identical in both the ML and BI trees, while the most distinct difference between both phylogenetic trees was the placement of $S$. chamaejasme. In the ML tree based on the ITS sequences, $S$. chamaejasme clustered within the Wikstroemia clade, but it was sister to Wikstroemia in the BI tree. The discordance between the plastid and nuclear phylogenies in this study may be due to phylogenetic sorting, convergence, unequal rates of evolution, long branch attraction, and introgression ${ }^{35}$. However, low branch node support in both the ITS-based ML and BI trees suggested that either the inclusion of additional nuclear gene sequences or the application of the restriction site-associated DNA sequence (RAD-Seq) technique that integrates up to $10 \%$ of the nuclear genome ${ }^{36}$ could $^{2}$ be helpful in resolving the phylogenetic relationships within Wikstroemia. Evidently, in this study, the use of a single nuclear gene sequence, i.e., ITS, which was suspected to be useful in delimiting many plants at the species level ${ }^{37}$, was insufficient for resolving the phylogenetic relationships between Stellera and Wikstroemia.

Members of Wikstroemia currently comprise species previously placed under Capura L., Daphne L., Diplomorpha Meisn., Daphnimorpha Nakai, Lonicera L., Passerina L., Restella Pobed., and Stellera L. ${ }^{1,38}$. The monotypic genus Stellera, which exhibits strikingly similar morphological characteristics, has troubled some taxonomists who compared it to Wikstroemia. At least five species were placed under Stellera before they were transferred to Wikstroemia; others were transferred to allied genera, such as Daphne, Diarthron and Thymelaea in the tribe Daphneae $^{38}$. This is understandable, as Stellera has a longer taxonomic history, i.e., back to 1747, when compared to other genera in the Daphneae. As a result, S. chamaejasme, as the type species, is the only species left in the genus. Based on the literature, we found that Wikstroemia has an interesting nomenclatural history in which two genera, Diplomorpha and Daphnimorpha, were synonymized and excluded. Combining Stellera with Wikstroemia was previously proposed by transferring the type species $S$. chamaejasme to the monotypic subgenus Chamaejasme ${ }^{11,39}$. However, the proposal was rejected, as Stellera has priority over Wikstroemia ${ }^{40}$, and based 


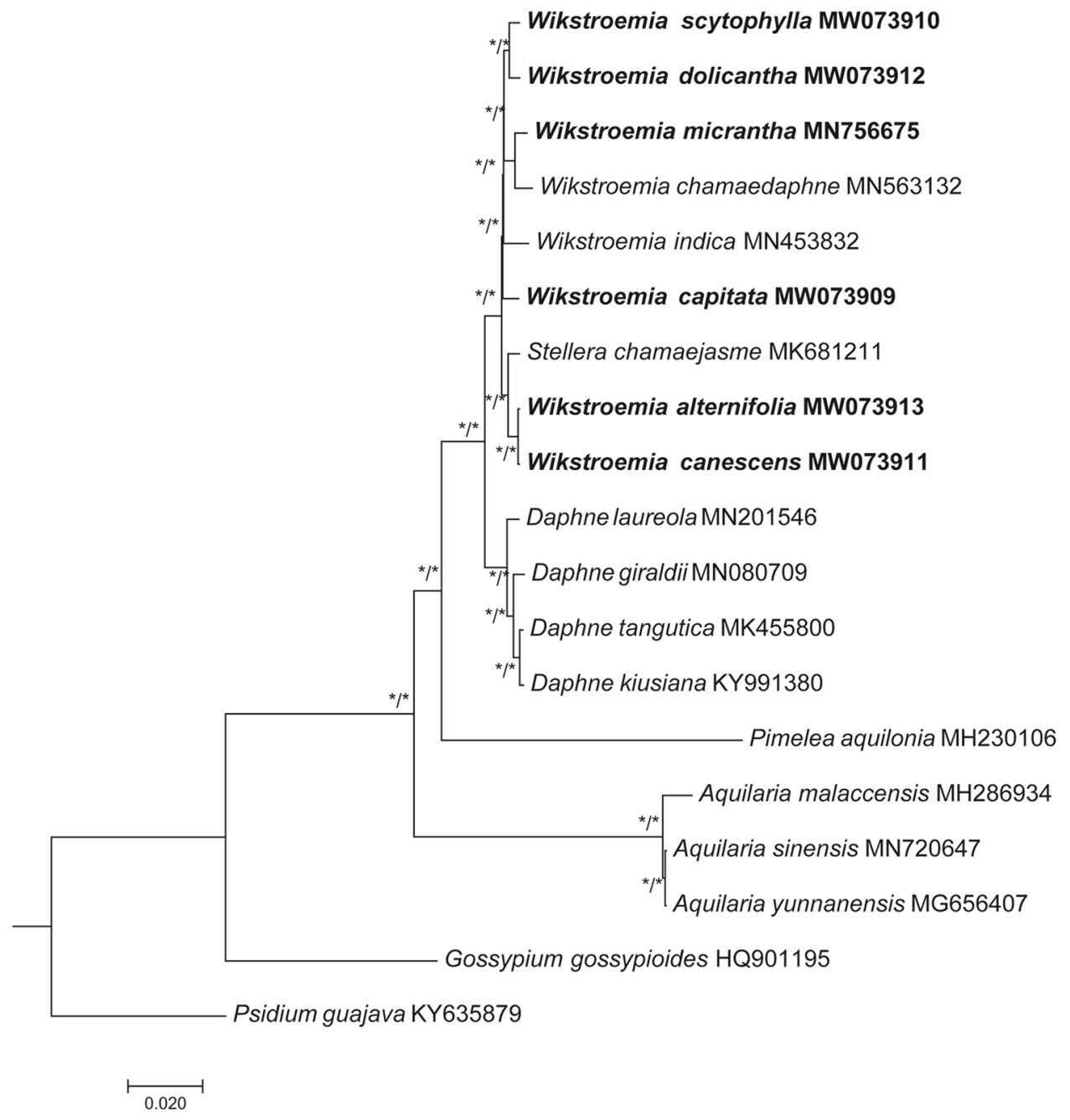

Figure 7. Maximum likelihood (ML) and Bayesian inference (BI) of Wikstroemia and allied genera based on the complete plastome sequences excluding the inverted repeat A (IRa) region, and a dataset of the intergenic spacer (IGS) regions of 17 taxa representing 5 genera of Thymelaeaceae, analysed separately. Branch nodes that were calculated with reliable support values (ML: bootstrap $\geq 75 \%$; BI: posterior probability $\geq 0.90$ ) are indicated with an asterisk $\left(^{*}\right)$. Sequences obtained through this study are indicated in bold; two species, Psidium guajava (KY635879) and Gossypium gossypioides (HQ901195), were included as outgroups.

on the Rules of Nomenclature, the combination can only be accepted if Stellera is proposed as a nomen genus rejiciendum (nom. gen. rejic.) ${ }^{12}$. Therefore, we do not exclude the possibility that Stellera should be synonymized with Wikstroemia. In that case, Wikstroemia would be synonymized under Stellera. One should not jump to such a conclusion rashly, based on the current situation, as the taxonomic dispute on whether Wikstroemia should be synonymized with Daphne is yet unresolved ${ }^{41}$. Unless Daphne is considered in a subsequent taxonomic treatment, based on the phylogenetic trees in this study, we could only conclude that Wikstroemia is not monophyletic and that Stellera is unquestionably closely related to Wikstroemia.

While phylogenetic analyses based on the plastome sequences of Wikstroemia have proven to be promising, we suggest that larger sampling is required to resolve the taxonomic dispute in Wikstroemia through a molecular approach. We foresee that the genetic information in the complete plastome sequences of Wikstroemia is deemed sufficient and could aid in the classification of Wikstroemia, both at the genus level and at the species level.

\section{Conclusion}

To the best of our knowledge, this study presents the first genome-scale analysis of species of Wikstroemia. The findings revealed high conservation of genes in the plastomes. The identification of highly variable gene regions in the plastome sequences of Wikstroemia could potentially be useful in resolving phylogenetic relationships in the genus. A strong sistership between Wikstroemia and the monotypic genus Stellera was present. The ML and BI trees based on the plastome sequences revealed that all the branch nodes for eight species of Wikstroemia included in the phylogenetic tree were supported with high bootstrap values and Bayesian posterior probabilities (ML: $\geq 90 \%$; BI: $\geq 95 \%$ ), while the ITS-based tree analyses could not properly resolve the phylogenetic relationship 

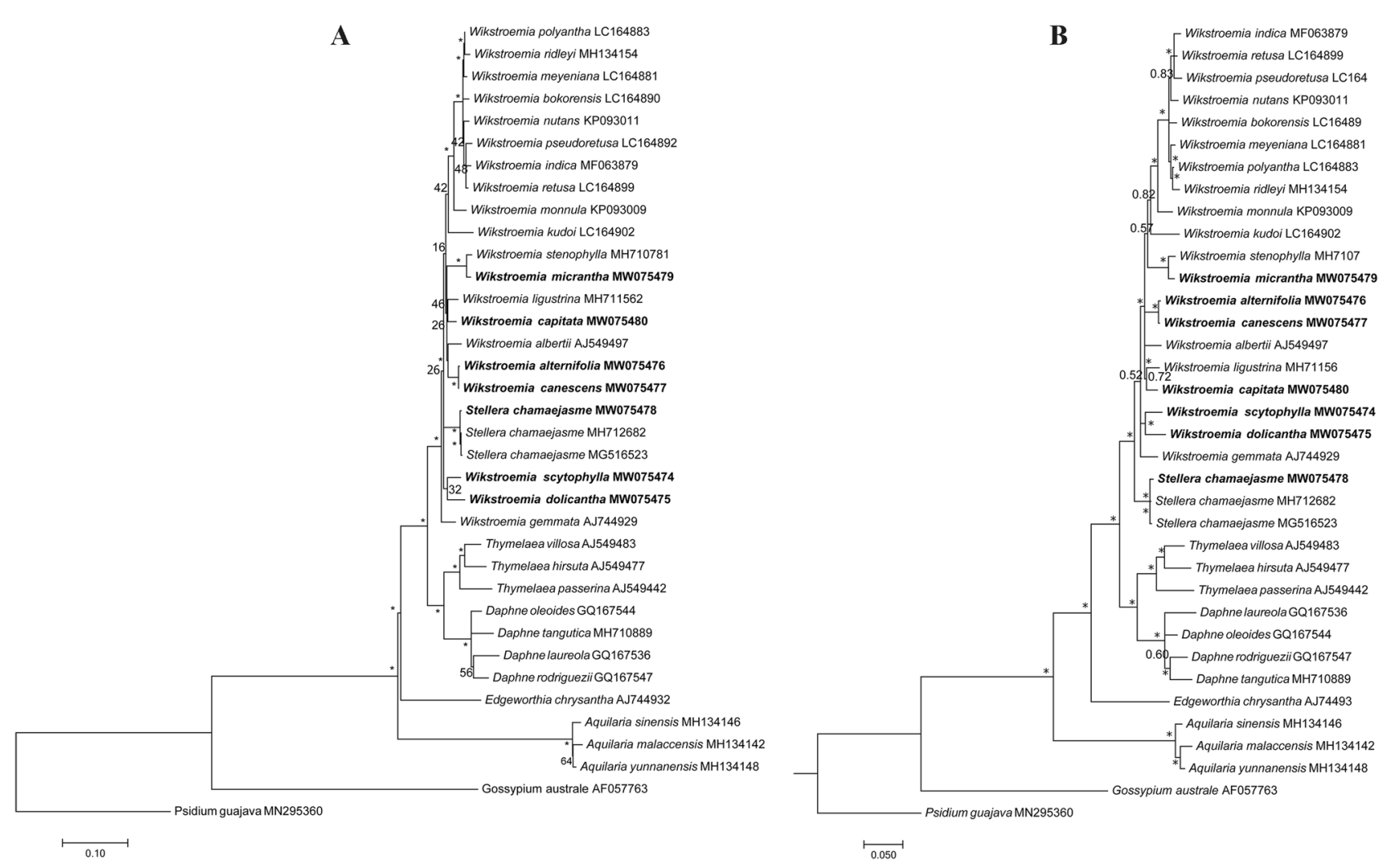

Figure 8. Phylogenetic analyses of Thymelaeaceae based on nuclear ribosomal DNA internal transcribed spacer (ITS) gene sequences of 34 taxa representing 6 genera of Thymelaeaceae. (A) Maximum-likelihood (ML) and (B) Bayesian inference (BI) tree analyses were conducted with 1000 bootstrap replicates. Branch nodes that were calculated with reliable support values (ML: bootstrap $\geq 75 \%$; BI: posterior probability $\geq 0.90$ ) are indicated with an asterisk (*). Two species, Psidium guajava (MN2953604) and Gossypium australe (AF057763), were included as outgroups.

between Stellera and Wikstroemia. Nevertheless, the molecular data obtained in this study will serve as a valuable resource for providing greater insights into the taxonomy and phylogeny of Thymelaeaceae.

\section{Materials and methods}

Plant materials and DNA extraction. Fresh leaf materials of six species of Wikstroemia, W. alternifolia, W. canescens, W. capitata, W. dolicantha, W. micrantha and W. scytophylla, were collected from botanical gardens and natural populations in China (Table 1). Species identification was carried out by Yonghong Zhang, and the voucher specimens were deposited in the Herbarium of Yunnan Normal University (YNUB) ${ }^{42}$. Based on the local guidelines and legislation on plant study, permissions for collections and research were unnecessary, as the samples were not collected in protected areas or recorded as threatened species. However, W. scytophylla was collected under permit record number w2021005, which was authorized in the Kunming Botanical Garden, Chinese Academy of Science, China. All collections are permitted and legal. Total genomic DNA was extracted using the Axygen AxyPrep Multisource Genomic Miniprep DNA kit (Corning, USA) following the manufacturer's protocol.

Plastome sequencing, assembly and annotation. A sequence library was constructed, and sequencing was performed on the Illumina HiSeq 2500-PE150 platform (Illumina, USA). All raw reads were filtered using NGS QC Toolkit version 2.3.3 with default parameters to obtain clean reads ${ }^{43}$. The plastome was de novo assembled using NOVOPlasty ${ }^{44}$ with the $r b c \mathrm{~L}$ gene sequence of Daphne kiusiana (GenBank accession KY991380) as the seed sequence. Gene annotation was performed in Geneious Prime ${ }^{28}$ using the complete plastome sequence of W. chamaedaphne (GenBank accession MN563132) as the reference genome. The circular physical map of the plastome was generated using OGDRAW ${ }^{45}$.

Repeat analyses. SSRs were identified using MISA-web ${ }^{46}$, in which parameters for the identification of perfect mono-, di-, tri-, tetra-, penta-, and hexanucleotide motifs were set for a minimum of 10, 5, 4, 3, 3, and 3 repeats, respectively. Long repeats, including forward, palindrome, reverse and complement repeats, were determined using REPuter ${ }^{47}$ with a Hamming distance of 3 and a minimal repeat size of $30 \mathrm{bp}$. 
Codon usage. Coding sequences of each plastome were extracted, and the RSCU was analysed using MEGA $7^{48}$.

Comparative genome and divergence analyses. The complete plastome sequences of two species of Wikstroemia, W. chamaedaphne (GenBank accession MN563132) and W. indica (GenBank accession MN453832), which were available in NCBI GenBank, were downloaded and included in subsequent analyses. By using the plastome sequences of $W$. chamaedaphne as the reference genome, nucleotide variation in the plastome sequence alignment of the eight species of Wikstroemia was visualized using mVISTA $^{49}$ in Shuffle-LAGAN mode. To detect the expansion and contraction of the IR region in the plastomes across the eight species, the IR/ SC boundaries of the plastomes were visualized using IRscope $e^{50}$. To detect the mutational hotspots and divergence regions in the plastomes of the eight species, sequence alignment of the plastome sequences was carried out using Geneious Prime ${ }^{28}$. Calculations of the nucleotide variability (Pi) among the eight plastomes were performed using DnaSP v5 ${ }^{51}$ with a window length of $1000 \mathrm{bp}$ and a step size of $500 \mathrm{bp}$.

Selection pressure analysis. The ratio of nonsynonymous to synonymous substitutions $\left(\mathrm{K}_{\mathrm{a}} / \mathrm{K}_{\mathrm{s}}\right)$ of protein-coding genes was calculated for Aquilaria sinensis (GenBank accession MN720647) and Wikstroemia capitata. Calculations were conducted for two sets of data: (1) shared genes analysed separately and (2) a combined dataset containing all shared genes. Prior to sequence alignment using MUSCLE embedded in MEGA $7^{48}$, the plastome sequence of $A$. sinensis was reannotated to ensure uniformity. For the combined dataset, the coding sequences were concatenated manually. Selection pressure acting on these genes was estimated using KaKs_Calculator $2.0^{52}$ based on the Yang and Nielsen codon frequency (YN) model, with parameters for the initial ratio of transition to transversion frequency $(\mathrm{K})$ set between 0.3 and $0.7 . \mathrm{A} \mathrm{K}_{\mathrm{a}} / \mathrm{K}_{\mathrm{s}}$ value equal to or less than 1.0 indicates the presence of purifying selection, in which changes in gene residues of amino acids that may favour excess synonymous versus nonsynonymous substitutions have been avoided, while the presence of positive selection is specified if the $\mathrm{K}_{\mathrm{a}} / \mathrm{K}_{\mathrm{s}}$ value is more than 1.0.

Polymerase chain reaction and Sanger sequencing. Polymerase chain reaction (PCR) amplification was carried out in a $20 \mu \mathrm{L}$ reaction volume using the ITS universal primer set: 5F: 5'-GGAAGTAAA AGTCGTAA-CAAGG-3' (forward) and 4R: 5'-TCCTCCGCTTATTGATATGC-3' (reverse). The PCRs for the nuclear ribosomal DNA ITS region contained $10 \mu \mathrm{L}$ of $2 \times$ Taq PCR Starmix with loading dye (Genstar Biosolutions, China), $0.4 \mu \mathrm{M}$ of each primer and $20 \mathrm{ng}$ of genomic DNA as a template. PCR amplifications were conducted on a T100 Thermal Cycler (Bio-Rad, USA), with initial denaturation at $93^{\circ} \mathrm{C}$ for 5 min; 40 cycles of denaturation at $93^{\circ} \mathrm{C}$ for $30 \mathrm{~s}$, annealing at $60^{\circ} \mathrm{C}$ for $30 \mathrm{~s}$, and extension at $72{ }^{\circ} \mathrm{C}$ for $30 \mathrm{~s}$; and a final extension at $72{ }^{\circ} \mathrm{C}$ for $5 \mathrm{~min}$. PCR products were sent for direct Sanger sequencing at both ends using an ABI 3730 DNA Analyzer (Applied Biosystems, USA).

Phylogenetic analyses. Phylogenetic analyses were conducted based on the plastome or gene sequences of 17 selected taxa from Thymelaeaceae. Two species, Psidium guajava (Myrtaceae; GenBank accession KY635879) and Gossypium gossypioides (Malvaceae; GenBank accession HQ901195), were included as outgroups. Seven datasets, including the (1) complete plastome sequences excluding IRa, (2) the total gene sequences containing protein-coding genes, tRNAs, and rRNAs that are shared by all species, (3) the intergenic spacer (IGS) sequences, (4) all protein-coding genes that are shared by all species, and (5) three additional subdatasets at the codon level for the first/second/third codons of each amino acid in the protein-coding sequences, were used to perform phylogenetic inferences. Part of the complete plastome sequences excluding the Ira and the targeted genic and intergenic regions in the plastomes, was extracted and concatenated using Geneious Prime ${ }^{28}$, while the first/second/third codons of each amino acid in the shared genes were extracted using MEGA $7^{48}$. Sequence alignment was carried out using MAFFT v7.45053. The ML tree was constructed based on all the sequence datasets using RAxML 8.2.11 $1^{54}$. The general-time-reversible (GTR) and gamma distributed $(+\mathrm{G})(+\mathrm{GTR}+\mathrm{G})$ DNA substitution model was selected, and all branch nodes were calculated under 1000 bootstrap replicates. BI analysis was conducted for all the datasets ${ }^{54,55}$. BI analysis was executed through the MrBayes ${ }^{55}$ pipeline available in the CIPRESS Science Gateway web portal ${ }^{56}$. Markov chain Monte Carlo (MCMC) was conducted with 2,000,000 generations, and sampling was collected every 100 cycles. The final tree was visualized using FigTree ${ }^{57}$ and edited manually.

The ITS sequences were aligned and manually trimmed for their primer sequences to obtain clean sequences. A total of 26 additional ITS sequences derived from members of the Thymelaeaceae were downloaded from the NCBI GenBank and MUSCLE-aligned against the ITS sequences of the six species of Wikstroemia used in this study using MEGA7 ${ }^{48}$. Two species, P. guajava (Myrtaceae; GenBank accession MN295360) and Gossypium australe (Malvaceae; GenBank accession AF057763), were included as outgroups. The alignment was trimmed using trimAL v1.2 $2^{58}$ with the gappyout method to reduce systematic errors produced by poor alignment. The optimal DNA substitution model for the ML analysis using the "Find Best DNA/Protein Model (ML)" function embedded in MEGA $7^{48}$ was calculated to be the Kimura two-parameter (K2P) model with the discrete Gamma model (+ G4) and invariant sites included $(+\mathrm{I})(=\mathrm{K} 2 \mathrm{P}+\mathrm{G}+\mathrm{I})$. ML analysis was performed using MEGA $7^{48}$ with 1000 bootstrap replicates. BI analysis was conducted with a previously described method ${ }^{55}$.

\section{Data availability}

The complete chloroplast sequences generated and analysed in this paper are available in GenBank (https://www. ncbi.nlm.nih.gov/genbank/, accession numbers listed in the text). 
Received: 23 November 2020; Accepted: 18 June 2021

Published online: 30 June 2021

\section{References}

1. Wang, Y. \& Gilbert, M. G. Wikstroemia. In Flora of China, Vol.13 (eds Wu, C. Y. et al.) 215-229 (Science Press and Missouri Botanical Garden Press, 2007).

2. Yum, H., Singer, B. W. \& Bacon, A. Coniferous wood pulp in traditional Korean paper between the 15th and 18th centuries AD. Archaeometry 51, 467-479 (2010).

3. Lin, L. D., Chang, F. C., Ko, C. H., Wang, C. Y. \& Wang, Y. N. Properties of enzyme pretreated Wikstroemia sikokiana and Broussonetia papyrifera bast fiber pulps. BioResources 10, 3625-3637 (2015).

4. Li, Y. M., Zhu, L., Jiang, J. G., Yang, L. \& Wang, D. Y. Bioactive components and pharmacological action of Wikstroemia indica (L.) C. A. Mey and its clinical application. Curr. Pharm. Biotechnol. 10, 743-752 (2009).

5. Helmi, H., Susanti, I., Agung, N. A. \& Kusen, S. Antibacterial activity of belilik (Brucea javanica (L.) merr) and benta (Wikstroemia androsaemofolia decne) to inhibit the growth of enteropathogenic bacteria. J. Biol. Res. 21, 35-40 (2016).

6. Kim, E. H., Kim, J. Y., Jung, J. Y. \& Son, S. W. Impact of habitat damage on Wikstroemia ganpi (Siebold \& Zucc.) Maxim. genetic diversity and structure. J. Agric. Life Sci. 52, 33-44 (2018).

7. Qian, S. J., Zhang, Y. H. \& Li, G. D. The complete chloroplast genome of a medicinal plant, Wikstroemia chamaedaphne (Thymelaeaceae). Mitochondrial DNA B. 5, 648-649 (2020).

8. Qian, S. J. \& Zhang, Y. H. Characterization of the complete chloroplast genome of a medicinal plant, Wikstroemia indica (Thymelaeaceae). Mitochondrial DNA B. 5, 83-84 (2020).

9. Mayer, S. S. Morphological variation in Hawaiian Wikstroemia (Thymelaeaceae). Syst. Bot. 16, 693-704 (1992).

10. Zhang, Y. Z., Sun, W. G., Jiang, X., Li, Z. M. \& Zhang, Y. H. Numerical taxonomy of the genera Daphne and Wikstroemia. Guihaia. 36, 61-72 (2016).

11. Domke, W. Zur Kenntnis einiger Thymelaeaceen. Notizblatt des Botanischen Gartens und Museums zu Berlin-Dahlem. 348-363 (1932).

12. Hou, D. Thymelaeaceae. In Flora Malesiana-Series 1, Spermatophyta. Vol. 6, (ed. Van Steenis C. G. G. J.) 1-48 (Wolters-Noordhoff Publishing, 1960).

13. Huang, S. Taxa nova Thymelaeacearum Sinicarum. Acta Bot. Yunnan. 7, 277-291 (1985).

14. Mayer, S. S. Artificial hybridization in Hawaiian Wikstroemia (Thymelaeaceae). Am. J. Bot. 78, 122-130 (1991).

15. Douglas, S. E. Plastid evolution: Origins, diversity, trends. Curr. Opin. Genet. Dev. 8, 655-661 (1998).

16. Xiong, Y., Xiong, Y., Jia, S. \& Ma, X. The complete chloroplast genome sequencing and comparative analysis of Reed Canary Grass (Phalaris arundinacea) and Hardinggrass (P. aquatica). Plants. 9, 748. https://doi.org/10.3390/plants9060748 (2020).

17. Ravi, V., Khurana, J. P., Tyagi, A. K. \& Khurana, P. An update on chloroplast genomes. Plant Syst. Evol. 271, 101-122 (2008).

18. Graham, S. W., Lam, V. K. Y. \& Merckx, V. S. F. T. Plastomes on the edge: The evolutionary breakdown of mycoheterotroph plastid genomes. New Phytol. 214, 48-55 (2017).

19. Li, X. et al. Plant DNA barcoding: From gene to genome. Biol. Rev. Camb. Philos. Soc. 90, 157-166 (2015).

20. Zhang, Y. H., Volis, S. \& Sun, H. Chloroplast phylogeny and phylogeography of Stellera chamaejasme on the Qinghai-Tibet Plateau and in adjacent regions. Mol. Phylogenet. Evol. 57, 1162-1172 (2010).

21. Herber, B. E. Pollen morphology of the Thymelaeaceae in relation to its taxonomy. Plant Syst Evol. 232, 107-121 (2002).

22. Herber, B. E. Thymelaeaceae. In The Families and Genera of Vascular Plants (eds Kubitzki, K. \& Bayer, C.) 373-396 (Springer, 2003).

23. Foster, C. S. P. et al. Molecular phylogenetics provides new insights into the systematics of Pimelea and Thecanthes (Thymelaeaceae). Aust. Syst. Bot. 29, 185-196 (2016).

24. Foster, C. S. P., Henwood, M. J. \& Ho, S. Y. W. Plastome sequences and exploration of tree-space help to resolve the phylogeny of riceflowers (Thymelaeaceae: Pimelea ). Mol. Phylogenet. Evol. 127, 156-167 (2018).

25. Jansen, R. K. \& Ruhlman, T. A. Plastid genomes of seed plants. In Genomics of Chloroplasts and Mitochondria Vol. 35 (eds Bock, R. \& Knoop, V.) 103-126 (Springer, 2012).

26. Li, X. et al. Complete chloroplast genome sequence of Magnolia grandiflora and comparative analysis with related species. Sci. China Life Sci. 56, 189-198 (2013).

27. Liu, X. et al. Complete chloroplast genome sequence and phylogenetic analysis of Quercus bawanglingensis Huang, Li et Xing, a vulnerable oak tree in China. Forests 10, 0587. https://doi.org/10.3390/f10070587 (2019).

28. Kearse, M. et al. Geneious basic: An integrated and extendable desktop software platform for the organization and analysis of sequence data. Bioinformatics 28, 1647-1649 (2012).

29. Tillich, M. et al. GeSeq-versatile and accurate annotation of organelle genomes. Nucleic Acids Res. 45, W6-W11 (2017).

30. Plunkett, G. M. \& Downie, S. R. Expansion and contraction of the chloroplast inverted repeat in Apiaceae subfamily Apioideae. Syst. Bot. 25, 648-667 (2000).

31. Raubeson, L. A. et al. Comparative chloroplast genomics: Analyses including new sequences from the angiosperms Nuphar advena and Ranunculus macranthus. BMC Genomics 8, 174. https://doi.org/10.1186/1471-2164-8-174 (2007).

32. Goulding, S. E., Olmstead, R. G., Morden, C. W. \& Wolfe, K. H. Ebb and flow of the chloroplast inverted repeat. Mol. Gen. Genet. 252, 195-206 (1996).

33. Wang, R. J. et al. Dynamics and evolution of the inverted repeat-large single copy junctions in the chloroplast genomes of monocots. BMC Evol. Biol. 8, 36. https://doi.org/10.1186/1471-2148-8-36 (2008).

34. Peery, R. M. Understanding angiosperm genome interactions and evolution: insights from sacred lotus (Nelumbo nucifera) and the carrot family (Apiaceae). University of Illinois at Urbana-Champaign (2015).

35. Soltis, D. E. \& Kuzoff, R. K. Discordance between nuclear and chloroplast phylogenies in the Heuchera group (Saxifragaceae). Evolution 49, 727-742 (1995).

36. Zimmer, E. A. \& Wen, J. Using nuclear gene data for plant phylogenetics: Progress and prospects II. Next-gen approaches. J. Syst. Evol. 53, 371-379 (2015).

37. Poczai, P. \& Hyvönen, J. Nuclear ribosomal spacer regions in plant phylogenetics: Problems and prospects. Mol. Biol. Rep. 37, 1897-1912 (2010).

38. The Plant List. The Plant List. http://www.theplantlist.org/ (3013).

39. Domke, W. Untersuchungen über die systematische und geographische Gliederung der Thymelaeaceen nebst einer Neubeschreibung ihrer Gattung. Bibl. Bot. 111, 1-151 (1934).

40. Rehder, A. Notes on the ligneous plants described by Léveillé from eastern Asia. J. Arnold Arboretum. 15, 267-326 (1934).

41. Halda, J. J. The Genus Daphne (SEN, 2001).

42. Thiers, B. Index Herbariorum: a global directory of public herbaria and associated staff. New York Botanical Garden's virtual herbarium. https://www.nybg.org/ (2018).

43. Patel, R. K. \& Jain, M. NGS QC Toolkit: A toolkit for quality control of next generation sequencing data. PLoS ONE 7, e30619. https://doi.org/10.1371/journal.pone.0030619 (2012).

44. Dierckxsens, N., Mardulyn, P. \& Smits, G. NOVOPlasty: De novo assembly of organelle genomes from whole genome data. Nucleic Acids Res. 45, e18. https://doi.org/10.1093/nar/gkw955 (2017). 
45. Lohse, M., Drechsel, O. \& Bock, R. OrganellarGenomeDRAW (OGDRAW): A tool for the easy generation of high-quality custom graphical maps of plastid and mitochondrial genomes. Curr. Genet. 52, 267-274 (2007).

46. Beier, S., Thiel, T., Münch, T., Scholz, U. \& Mascher, M. MISA-web: A web server for microsatellite prediction. Bioinformatics 33, 2583-2585 (2017).

47. Kurtz, S. et al. REPuter: The manifold applications of repeat analysis on a genomic scale. Nucleic Acids Res. 29, 4633-4642 (2001).

48. Kumar, S., Stecher, G. \& Tamura, K. MEGA7: Molecular evolutionary genetics analysis version 7.0 for bigger datasets. Mol. Biol. Evol. 33, 1870-1874 (2016).

49. Frazer, K. A., Pachter, L., Poliakov, A., Rubin, E. M. \& Dubchak, I. VISTA: Computational tools for comparative genomics. Nucleic Acids Res. 32, W273-279 (2004).

50. Amiryousefi, A., Hyvönen, J. \& Poczai, P. IRscope: An online program to visualize the junction sites of chloroplast genomes. Bioinformatics 34, 3030-3031 (2018).

51. Librado, P. \& Rozas, J. DnaSP v5: A software for comprehensive analysis of DNA polymorphism data. Bioinformatics 25, 1451-1452 (2009).

52. Wang, D., Zhang, Y., Zhang, Z., Zhu, J. \& Yu, J. KaKs_Calculator 2.0: A toolkit incorporating gamma-series methods and sliding window strategies. Genom. Proteomics Bioinform. 8, 77-80 (2010).

53. Katoh, K. \& Standley, D. M. MAFFT multiple sequence alignment software version 7: Improvements in performance and usability. Mol. Biol. Evol. 30, 772-780 (2013).

54. Guindon, S. et al. New algorithms and methods to estimate maximum-likelihood phylogenies: Assessing the performance of PhyML 3.0. Syst Biol. 59, 307-321 (2010).

55. Ronquist, F. et al. MrBayes 3.2: Efficient Bayesian phylogenetic inference and model choice across a large model space. Syst. Biol. 61, 539-542 (2012).

56. Miller, M. A., Pfeiffer, W. \& Schwartz, T. Creating the CIPRES Science Gateway for inference of large phylogenetic trees. Gateway Computing Environments Workshop (GCE), New Orleans, LA, USA, 1-8. https://doi.org/10.1109/GCE.2010.5676129 (2010).

57. Rambaut, A. FigTree v1.4. http://tree.bio.ed.ac.uk/software/figtree (2018).

58. Capella-Gutiérrez, S., Silla-Martínez, J. M. \& Gabaldón, T. trimAl: A tool for automated alignment trimming in large-scale phylogenetic analyses. Bioinformatics 25, 1972-1973 (2009).

\section{Acknowledgements}

The authors thank Dr. David E. Boufford of Harvard University Herbaria for ideas and assistance provided during manuscript preparation. One sample, W. scytophylla, was obtained from the Kunming Botanical Garden, Kunming Institute of Botany, Chinese Academy of Sciences (permit number w2021005), with help from Dr. Yang Niu. This work was supported by the National Natural Science Foundation of China (31760048) and the Fundamental Research Funds for the Central Universities (33000-31611215).

\section{Author contributions}

Y.H.Z. collected the plant materials and performed the experiments. L.F.H. assembled the sequences and analysed the data. L.F.H. wrote the manuscript. Y.H.Z and S.Y.L. conceived the research and revised the manuscript. All authors read and approved the final manuscript.

\section{Competing interests}

The authors declare no competing interests.

\section{Additional information}

Supplementary Information The online version contains supplementary material available at https://doi.org/ 10.1038/s41598-021-93057-3.

Correspondence and requests for materials should be addressed to Y.Z. or S.Y.L.

Reprints and permissions information is available at www.nature.com/reprints.

Publisher's note Springer Nature remains neutral with regard to jurisdictional claims in published maps and institutional affiliations.

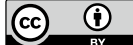

Open Access This article is licensed under a Creative Commons Attribution 4.0 International License, which permits use, sharing, adaptation, distribution and reproduction in any medium or format, as long as you give appropriate credit to the original author(s) and the source, provide a link to the Creative Commons licence, and indicate if changes were made. The images or other third party material in this article are included in the article's Creative Commons licence, unless indicated otherwise in a credit line to the material. If material is not included in the article's Creative Commons licence and your intended use is not permitted by statutory regulation or exceeds the permitted use, you will need to obtain permission directly from the copyright holder. To view a copy of this licence, visit http://creativecommons.org/licenses/by/4.0/.

(C) The Author(s) 2021 